\title{
NEUROPATHOLOGY OF TWO BRAZILIAN AUTOPSIED CASES OF TROPICAL SPASTIC PARAPARESIS / HTLV-I ASSOCIATED MYELOPATHY (TSP/HAM) OF LONG EVOLUTION
}

\author{
Carlos Maurício de Castro-Costa', René Dom², Herwig Carton ${ }^{3}$, \\ Patrick Goubau4, Terezinha de Jesus Teixeira Santos', \\ Márcia Valéria Pitombeira Ferreira ${ }^{5}$, Francisco Ursino da Silva Neto ${ }^{5}$
}

\begin{abstract}
We report on a neuropathological analysis of two cases of TSP/HAM originating from Brazil. These two cases had, respectively, an evolution of 13 and 40 years. The main neuropathological findings consisted of spinal cord atrophy, mainly the lower thoracic cord, diffuse degeneration of the white and grey matter, rare foci of mononuclear and perivascular cuffs, and hyaline hardening of arteriolae. The supraspinal structures were normal, excepting for a slight gliosis in the cerebellum. An analysis on the long evolutive cases as described in the literature is outlined in this study.
\end{abstract}

KEY WORDS: TSP/HAM long evolution, neuropathological findings, spinal cord, rare inflammatory infiltration.

\begin{abstract}
Neuropatologia de dois casos brasileiros autopsiados de paraparesia espástica tropical / mielopatia associada ao HTLV-I (PET/MAH) de longa evolução

RESUMO - Relatamos a análise neuropatológica de dois casos de PET/MAH originários do Brasil. Estes dois casos tinham, respectivamente, uma evolução de 13 e 40 anos. 0 principais achados neuropatológicos consistiam de atrofia da medula espinhal, principalmente da medula torácica baixa, degeneração difusa das substâncias branca e cinzenta, raros focos de infiltrado mononuclear e perivascular, e endurecimento hialínico das arteriolae. As estruturas supra-espinhais eram normais, exceto por uma ligeira gliose do cerebelo. Uma análise dos casos de longa evolução descritos na literatura é salientada neste estudo.
\end{abstract}

PALAVRAS-CHAVE: PET/MAH longa evolução, achados neuropatólogicos, medula espinhal, infiltração inflamatória rara.

There are around 34 autopsied TSP/HAM cases described in the world ${ }^{1-17}$. This number of cases is limited, since León et al. ${ }^{18}$, in a world meta-analytical analysis, reported on 1261 cases of TSP/HAM. All patients had similar clinical picture with gait disturbance and pyramidal signs as the clinical core, besides sensitive and sphincter impairment, characteristic of TSP/HAM. Exceptionally, some cases with cognitive impairment have been described ${ }^{15,19}$. Moreover, all patients were serologically positive in serum or CSF, or both, as shown by screening tests (EIA or PA), confirmatory tests (Western blot) and, in some cases, by molecular tests (PCR).
These autopsied cases included patients with evolution ranging from 9 month ${ }^{13}$ to 28 years ${ }^{8}$. Iwasaki $i^{8}$, in an analysis of 10 autopsied TSP/HAM cases from Japan, delineated three histopathological stages in the evolution of the patients: 1) from 0 to 3 years with predominant inflammatory changes besides degenerative picture; 2 ) from 4 to 6 years, with predominant degenerative changes and small number of inflammatory cells; and 3) from 9 to 28 years with only monotonous degeneration of white matter with virtually absent inflammatory cells.

Taking this into consideration, we were interested in analyzing the histopathological aspects of the long

\footnotetext{
${ }^{1}$ Service of Neurology (University Hospital) / Laboratory of Experimental Neurology (Department of Physiology and Pharmacology), Federal University of Ceará, Fortaleza CE, Brazil; ${ }^{2}$ Department of Neuropathology, Katholieke Universiteit Leuven, Leuven, Belgium; ${ }^{3}$ Department of Neurology, Katholieke Universiteit Leuven, Leuven, Belgium; ${ }^{4}$ Unit of Virology, Université Catholique de Louvain, Louvain, Belgium; ${ }^{5}$ Department of Pathology and Legal Medicine, Federal University of Ceará, Fortaleza CE, Brazil.
}

Received 26 November 2001. Accepted 19 February 2002.

Dr. Carlos Maurício de Castro Costa - Laboratorio de Neurologia Experimental e Neurofisiologia/DFF/FM/UFC - Rua Coronel Nunes de Melo 1127 - 60.430-270 Fortaleza CE - Brasil - Caixa Postal 3157 - FAX: 558528883 33. E-mail: pst016@sec.secrel.com.br 


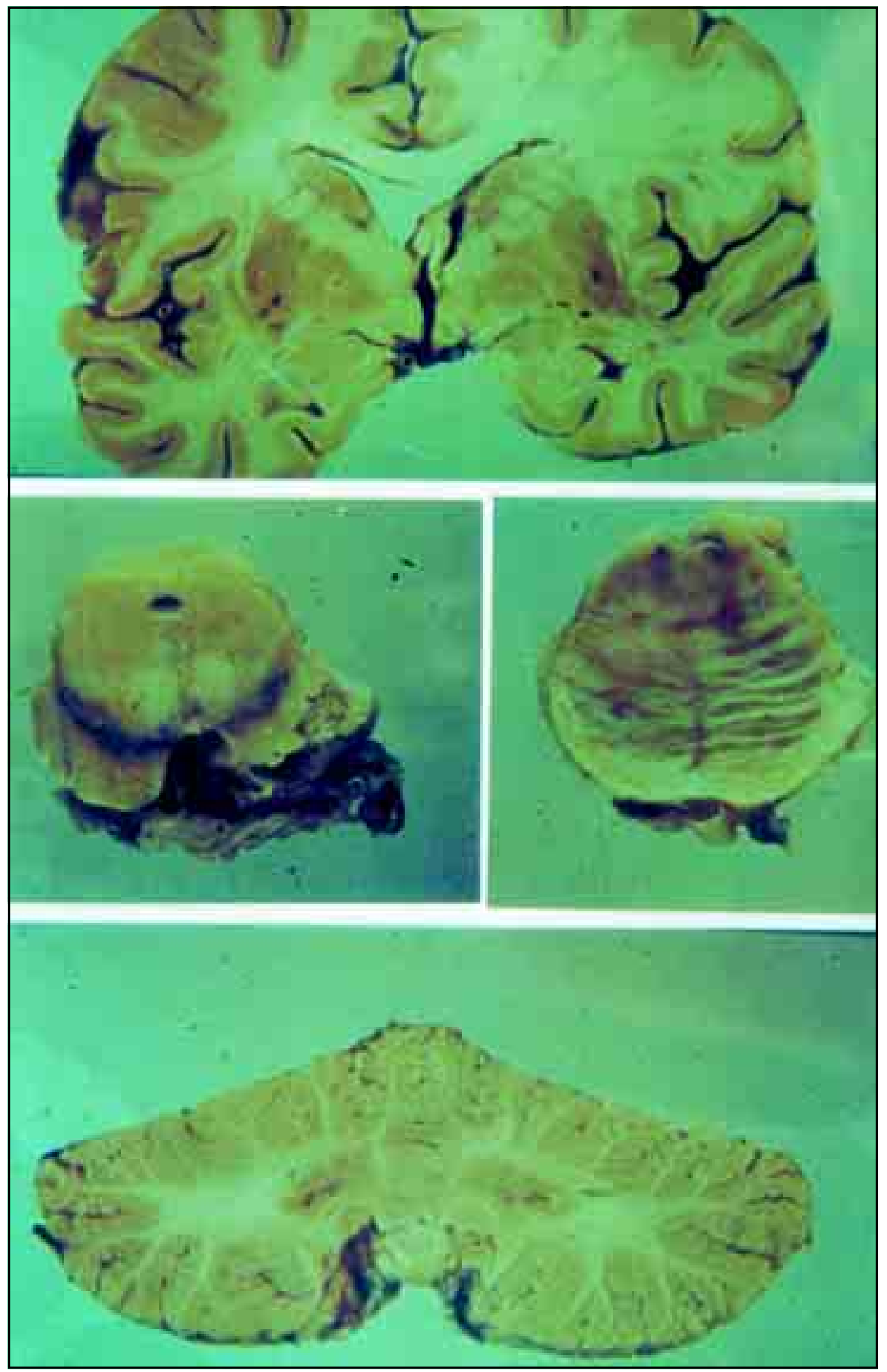

Fig 1. Macroscopically normal brain, mesencephalon, pons and cerebellum.

evolutive cases, which go on expressing clinically the characteristics of TSP/HAM. For this, we report, in this work, two autopsied cases from Brazil, with the aim of describing: 1) the histological picture of these long evolutive cases; 2 ) the comparison with the pre- viously described cases of the literature, in order to outline the common and uncommon aspects; and 3) the possibility to make suggestions on the meaning of possible uncommon neuropathological findings. 


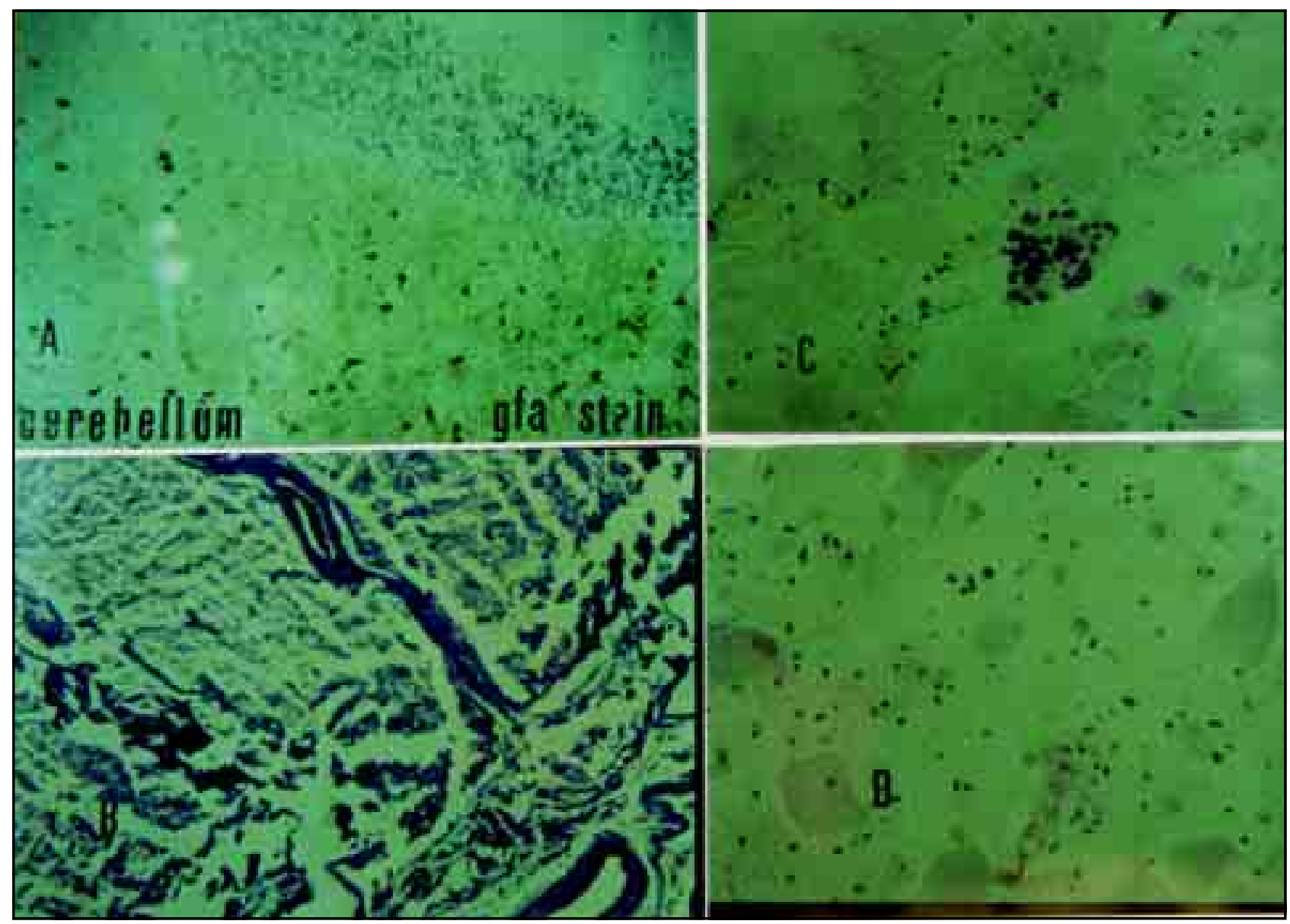

Fig 2. (A) Reactive astrocytes in cerebellum (GFAP x200). (B) Complete demyelination of anterior thoracic corticospinal tracts. Normal anterior spinal artery (Klüver-Barrera x200). (C) Small focus of inflammatory cells in the grey matter at thoracic level (HE x200). (D) Normal looking anterior horn cells at the lower lumbar level (HE x200).

\section{CASES}

Case 1 - F.C.R., a mulatto female, without antecedents of blood transfusion, developed a progressive paraparesis associated with pain in the knees. After 4 years, she developed sphincter disturbances, and became wheelchairbound after 8 years (EDSS $=8$ ). The neurological examination showed a spastic paraparesis with hyperreflexia of the upper and lower limbs with bilateral Babinski sign. There was also pain and tactile hypoesthesia in the feet. Other etiologies were excluded by imaging and CSF studies. The study of the somatossensory evoked potentials showed an accentuated delay of the proprioceptive conduction in the posterior columns and/or medial lemniscus. She died of cholera at age 69 , after 13 years of evolution.

Case 2 - W.S.R., also a mulatto female, developed a slowly progressive spastic paraparesis along 34 years associated with tardive sphincter disturbance. Afterwards, she became wheelchair-bound and, at that time, she also complained of severe arthralgia. On neurological examination, she had spastic paraplegia with bilateral Babinski and Hoffmann signs, hyperreflexia of the upper and lower limbs, and clonus in the feet. Her sensibility was normal. She had urinary incontinence. The CSF and cervico-lumbar myelography were normal. She died of infectious complications of ulcerative cholitis at age 82 , after 40 years of evolution.

Both cases were HTLV-I positive, serologically (EIA and WB) and molecularly (PCR).

\section{Pathological findings}

The autopsy of the first case (FCR), with 13 years of evolution, revealed an ascitis, pleural effusion with bilateral pulmonary edema and congestion and steatosis of the liver. She died of hydroelectrolitic disturbance. The neuropathological analysis of this case showed, macroscopically, a normal brain, brainstem and cerebellum (Fig 1). Microscopically, there was a slight gliosis of the cerebellum as shown by GFAP staining (Fig 2A). The spinal cord showed diffuse degeneration of the white and grey matter at the cervico-thoraco-lumbar level (Fig 2B). Foci of mononuclear cells or perivascular cuffs were rare but existent (Fig 2C). There was preservation of anterior horn cells of the spinal cord (Fig 2D).

The autopsy of the second case (WSR), with 40 years 


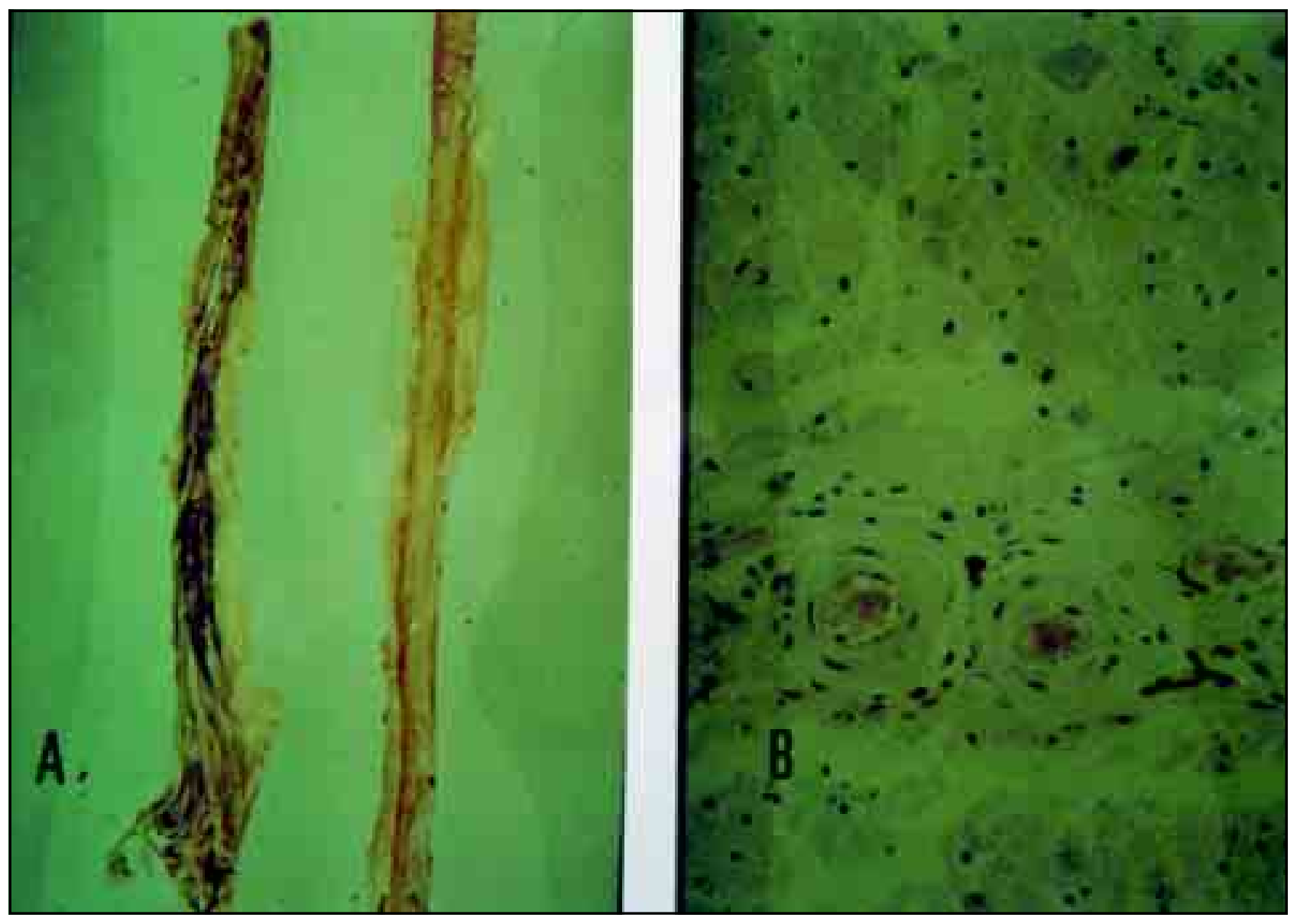

Fig 3. (A) Macroscopically normal spinal cord as compared with an atrophic spinal cord of a TSP/HAM patient (WSR). (B) Grey matter at thoracic level with thickening of the vascular walls and perivascular infiltration. A few anterior horn cells are preserved but pycnotic (HE x200).

of evolution, presented a hemorrhagic mucosa of the esophagus, the lung showed areas of hemorrhagic and alveolar proteinase (acute pneumocitis), the colon revealed areas of ulceration and the liver was atrophic. The patient died of hydroelectrolitic disturbance for extensive ulcerative rectocholitis. Neuropathologically, in this second case, a diffuse atrophy of the brain and narrowing of the thoraco-lumbar cord were found (Fig 3A). Slight lymphocytic infiltrates were seen in the meninges and around the parenchymal vessels, besides a hyaline hardening of the arteriolae of the brain, cerebellum and spinal cord, with preservation of anterior horn cells (Fig 3B).

\section{DISCUSSION}

The autopsied cases of long evolution are very few in the literature ${ }^{8,10-12,15,17}$. The two Iwasaki's ${ }^{8}$ cases of long evolution ( 19 and 28 years, respectively) were typical clinical TSP/HAM and, neuropathologically, "neither lymphocytic nor monocytic cell infiltration was seen in markedly devastated and shrunken parenchymal tissues". However, the paraventricular cerebral white matter showed mononuclear cell infil- tration with foci of myelin pallor and gliosis. The case described by Ogata et al. ${ }^{10}$ had an evolution of 36 years and, neuropathologically, showed a severe atrophy of the lower thoracic spinal cord, a loss of myelin and axons in the lateral column and, to a lesser degree, in the posterior column, posterior spinocerebellar tract and the anterior funiculus. Moreover, hyaline thickening of the blood vessels of the thoracic spinal cord and astrocytosis were seen. No inflammatory infiltration was observed. In the cervico-lumbar cord, the lateral column was affected preferentially, with lesser expression. Mild, similar and ill-defined demyelination lesions were also seen in the periventricular white matter of the brain. From five cases, Umehara et al. ${ }^{11}$ described two cases with evolution of 9 and 10 years, respectively, which showed a monotonous degeneration of both lateral funiculi of the spinal cord associated with a few inflammatory cells in the subarachnoid and perivascular spaces. Wu et al.' $\mathrm{s}^{12}$ case had an evolution of 25 years and the neuropathological findings revealed focal mild perivascular lymphocytic infiltration in the white 
matter of temporal lobe, inferior olive and in the leptomeninges of the cerebellum. There was a severe atrophy of the whole spinal cord, with demyelination of the lateral and anterior funiculi, mainly at the thoracic level where axons were prominently lost. The leptomeninges showed dense fibrosis and chronic vascular inflammatory infiltration. In the parenchyma (white matter), a perivascular and parenchymal mononuclear inflammatory infiltration was also present. Severe gliosis was evident in the white matter. Besides the uncommon presence of inflammatory infiltration at this time of evolution, Wu et al. ${ }^{12}$ describe, in this case, a focal thoracic loss of anterior horn cells, and some neurons with chromatolytic changes or cytoplasmic vacuolation and neuroaxonal spheroids. In Cartier et al. ${ }^{15}$ series, only one TSP/HAM patient had a long evolution of 17 years. The neuropathological aspects of this case consisted of spinal cord atrophy, mainly in the thoracic region, and thickening of the meninges. The histological analysis revealed a loss of myelin and axon in the lateral columns, and neuroaxonal spheroids. The axomyelinic degeneration of the pyramidal tracts was proeminent in the dorsal and lumbar segments, with little involvement of the cervical region. There was also involvement of the anterior tracts and posterior columns. In this case, there was a mild chromatolysis and pycnosis of the motor neurons, thickening of the adventitia and lymphocytic cuffs. In the medulla, there was some meningeal thickening, some degree of atrophy of the pyramids, and, demyelination with axonal loss and gliosis. The pons, midbrain and cerebellum did not show significant changes in the parenchyma. In the basal nuclei and thalamus, some neurons had cytoplasmic birefringent eosinophilic bodies. The motor cortex showed satellitosis. Peripherally, the spinal ganglia exhibited slight lymphocytic infiltration, and the peripheral nerves and muscles were normal. Aye et al. ${ }^{17}$ analyzed four cases with, respectively, 7, 9, 15 and 24 years of illness duration, with incapacitating clinical signs in the three first ones, without, however, clinical cerebral signs. Their long evolutive cases (15 and 24 years, respectively) had degeneration of the lateral corticospinal tract and of the spinocerebellar or spinothalamic tracts. Histopathologically, there were very few inflammatory cells in the spinal cord, with, however, marked fibrosis of the blood vessel wall, especially in the thoracic lateral column. Besides these spinal lesions, there were as well few inflammatory infiltrates, extensive fibrosis of small and large blood vessels in cerebrum.
In short, the neuropathological description of those long evolutive cases revealed that the lower thoracic spinal cord was mainly affected, with lesser impairment of the cervico-lumbar cord despite the long evolution. Moreover, contrarily to Iwasaki's $s^{8}$ pathological classification of the cases, some degree of inflammatory infiltration has been described by Umehara et al. ${ }^{11}$, Wu et al. ${ }^{12}$, Cartier et al. ${ }^{15}$, Aye et al. ${ }^{17}$ and in our cases, what may arise new considerations on the pathogenetic and evolutive mechanisms of this condition. Supraspinal affection is not common, and when present, it is not correlated with clinical symptoms. However, some of the authors have shown lymphocytic infiltration of temporal lobe, olives and cerebellum ${ }^{12}$, presence of eosinophilic bodies in the basal nuclei and thalamus besides satellitosis of the motor cortex ${ }^{15}$, and paraventricular mononuclear cell infiltration ${ }^{8}$. On the other hand, Aye et al. ${ }^{17}$ evidenced a brain inflammatory involvement mainly in cases with active chronic inflammation ( 7 and 9 years of evolution) but not in inactive chronic inflammation (15 and 21 years of evolution). Our cases evidenced only astrocytic reaction of the cerebellum. In fact, the meaning of these encephalic lesions is still unknown, but their understanding may possibly contribute for the definition of this condition as a multisystemic neurological syndrome. In this sense, Taguchi et al. ${ }^{20}$ reported recently on a case of encephalopathy associated to HTLV-I that they suppose distinct from ATLL and TSP/HAM, this way, proposing a new cerebral entity associated to HTLV-I. Further studies are so needed to clarify such matters, including neuropathological analysis of more human cases, as well longitudinal and chronological studies with experimental HAM rats.

\section{REFERENCES}

1. Akizuki S, Nakazato O, Higuchi $Y$, et al. Necropsy findings in HTLVI associated myelopathy. Lancet 1987;1:156-157.

2. Akizuki S, Yoshida S, Setoguchi M, et al. The neuropathology of human T-lymphotropic virus type I associated myelopathy. In Román GC, Vernant JC, Osame M (eds). HTLV-I and the nervous system. New York: Alan R. Liss, 1989:253-260.

3. Picardo P, Ceroni M, Rodgers-Johnson P, et al. Pathological and immunological observations on tropical spastic paraparesis in patients from Jamaica. Ann Neurol 1988;23(Suppl.):S156-S160.

4. Furuzono H, Nakazato O, Goto K, Akizuki S, Okajima T. An autopsy case of HTLV-I associated myelopathy (HAM). Clin Neurol (Japan) 1989;29:349-354.

5. Kobayashi I, Ota K, Yamamoto K, Murakami H, Maruyama S. An autopsy case of HTLV-I associated myelopathy. Neurol Med 1989;30:409412.

6. Izumo S, Usuku K, Osame M, et al. The neuropathology of HTLV-I associated myelopathy in Japan: report of an autopsy case and review of the literature. In Román GC, Vernant JC, Osame M (eds). HTLV-I and the nervous system. New York: Alan R. Liss, 1989:261-267.

7. Izumo S, Ijichi T, Higuchi I, Tashiro A, Takahashi K, Osame M. Neuropathology of HTLV-I-associated myelopathy: a report of two autopsy cases. Acta Paediatr Jpn 1992;34:358-364. 
8. Iwasaki Y. Pathology of chronic myelopathy associated with HTLV-I infection (HAM/TSP). J Neurol Sci 1990;96:103-123.

9. Bhigjee AI, Wiley CA, Wachsman W, et al. HTLV-I associated myelopathy: clinicopathologic correlation with localization of provirus to spinal cord. Neurology 1991;41:1990-1992.

10. Ogata A, Nagashima K, Tashiro K, Miyakawa A, Mikuni CH. MRI-pathological correlate of brain lesions in a necropsy case of HTLV-I associated myelopathy. J Neurol Neurosurg Psychiatry 1993;56:194-196.

11. Umehara F, Izumo S, Nakagawa M, et al. Immunocytochemical analysis of the cellular infiltrate in the spinal cord lesions in HTLV-1 associated myelopathy. J Neuropathol Exp Neurol 1993;52:424-430.

12. Wu E, Dickson DW, Jacobson S, Raine CS. Neuroaxonal dystrophy in HTLV-I associated myelopathy / tropical spastic paraparesis: neuropathologic and neuroimmunologic correlations. Acta Neuropathol 1993;86:224-235.

13. Yoshioka A, Hirose G, Veda Y, Nishimura Y, Sakai K. Neuropathological studies of the spinal cord in early stage HTLV-I associated myelopathy (HAM). J Neurol Neurosurg Psychiatry 1993;56:1004-1007.

14. De Castro-Costa CM, Dom R, Carton H, Goubau P, Ferreira MVP, Neto FUS. A pathological analysis of two first Brazilian autopsied cases of HAM/TSP (abstract). J Acquir Immune Defic Syndr Hum Retrovirol 1995; 10:229.
15. Cartier LM, Cea G, Vergara C, Araya F, Born P. Clinical and neuropathological study of six patients with spastic paraparesis associated with HTLV-I: an axomyelinic degeneration of the central nervous system. J Neuropathol Exp Neurol 1997;56:403-413.

16. Leite AC, Serapião MJ, Neves ES, et al. Autopsy findings in two cases of HTLV-I myelopathy (HAM/TSP). In Abstracts of VIII ${ }^{\text {th }}$ International Conference on Human Retrovirology: HTLV. Rio de Janeiro, Brazil, Jun. 1997, CS 15.

17. Aye MM, Matsuoka E, Moritoyo T, et al. Histopathological analysis of four autopsy cases of HTLV-I-associated myelopathy / tropical spastic paraparesis: inflammatory changes occur simultaneously in the entire central nervous system. Acta Neuropathol 2001;100:245-252.

18. León-S FE, De Castro-Costa CM, Gaffga M. Discrepancy, coincidence or evidence in chronic idiopathic spastic paraparesis throughout the world: a meta-analysis of 2811 patients. Arq Neuropsiquiatr 1997;55:530-535.

19. Silva MTT, Araújo AQ-C, Oliveira ALA, Mattos P, Campos AA, Luiz RR. Neuropsychological evaluation in HTLV-I-associated myelopathy. AIDS Res Hum Retroviruses 2001;17(Suppl. 1):S-63.

20. Taguchi H, Takemoto S. HTLV-I associated encephalopathy: a new clinical entity? AIDS Res Hum Retroviruses 2001;17(Suppl. 1):S-66. 